\title{
Fog forecasting and service for highways
}

\author{
D. P. Ding, X. Li, H. L. You, Y. Ding, C. Han, T. Fong \& Z. Xie \\ Beijing Weather Information Service, Beijing, China
}

\begin{abstract}
Fog leads to dangerous driving conditions. Along the highway of the coast of the Bohai gulf, the occurrence frequency is higher than other places in the Beijing area. Nowadays, numerical weather prediction is widely used in China. Based on numerical model (MM5), the statistical method is applied to build a forecast model for seven stations along the highway. When fog is forecast it is tracked by satellite images. Beijing Weather Information Service provides forecast products each day via various media. These products include two fog forecasts of the next $24 \mathrm{hr}$ period for each site along the highway. Also, there are four real time observations and 48 images of geostationary meteorological satellite of fog products in the Huabei region, processed with the combination of multi-channel sensors in order to make up the shortage of the AWS (Automatic Weather Station). The warnings are issued to highway managers and to the general public if fog occurs.
\end{abstract}

Keywords: fog forecast, satellite image, tracking fog, transportation service.

\section{Introduction}

Based on investigations of the highway, the traffic accidents caused by fog have the largest proportion in all traffic accidents and lead to the greatest losses in both people's life and property every year. Consequently, accurate prediction of fog along the highway is demanded by decision-making departments and the general public.

Fog directly affects visibility. In meteorological terms, horizontal visibility (V) $1 \mathrm{~km}<\mathrm{V} \leq 10 \mathrm{~km}$ is called a light fog, $500 \mathrm{~m} \leq \mathrm{V} \leq 1 \mathrm{Km}$ is called fog, and $\mathrm{V}<500 \mathrm{~m}$ is called a heavy fog.

There are mountains situated in the northwestern area of Beijing and plains in the southeast neighboured to Bohai Sea. The foggy days increase gradually from Beijing (22.9d/a) to Bohai gulf (30d/a). In general, the number of foggy days in 
autumn is larger than in other seasons. The diurnal variation of fog is obvious. The highest frequency of fog occurrence is usually in the early morning [1].

At present, numerical weather prediction (NWP) has been widely used in China. A meso-scale model (MM5 Model) was modified by Beijing Meteorological Bureau (BMB). Although the trend of atmospheric circulation could be well forecasted by this model, there are no special products for fog forecasting. Based on MM5 products, the statistical method was applied to build a fog forecast model.

\section{Historical data classification}

Fog is a small probability event and local weather phenomenon against the background of large scale synoptic patterns, which is affected by geographical environment, weather conditions, diurnal variation and so on [2,3]. A statistical forecast method is developed in this paper. Firstly, historical samples have been classified based on synoptic meteorology, then Euclidean Distance is used as a prediction model.

The data of 7 weather stations (2000-2005) along the Jing-Jintang Highway (Beijing-Tianjin-Tanggu) are collected in this paper (Fig.1). According to seasons (winter, spring, summer and autumn), fixed hours (02:00, 08:00, 14:00, 20:00), surface wind directions (east wind, north wind, south wind), the historical data were classified as a database for every station.

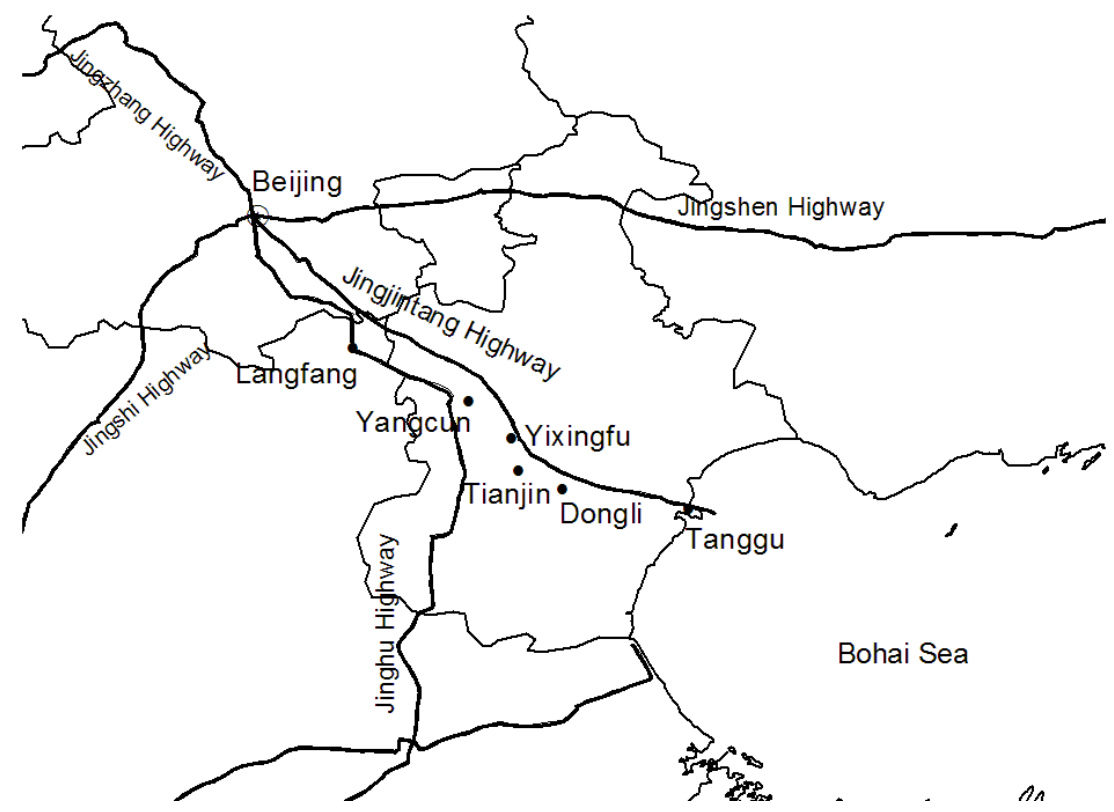

Figure 1: Geographical locations of 7 weather stations along the Jing-Jintang Highway. 


\section{Brief introduction of fog forecast model}

Generally, under a certain synoptic pattern, the formation of fog depends mostly on four elements: wind speed, air pressure, air temperature and relative humidity $[4,5]$. Therefore, it is supposed that if the weather elements in the future are similar to one of the historical samples, the visibility of the historical sample will be considered as the one in the future. By using Cluster Analysis, a similarity distance (Euclidean Distance) between products of MM5 and historical samples is calculated. The basic calculative formula is as follows:

$$
D=\sqrt{\sum_{i=1}^{n}\left(y_{i}-x_{i}\right)^{2}}
$$

where D is the Euclidean Distance between two samples, $y_{\mathrm{i}}$ is the weather element of No. $i$ in NWP, $x_{\mathrm{i}}$ is the weather element of No. $i$ in historical samples. The minimum Euclidean Distance value is adopted. That means the visibility of the future is considered to be the most similar to one of the visibilities in the past. If there are one or more minimum distances, it is necessary to distinguish which one is the closest for forecaster.

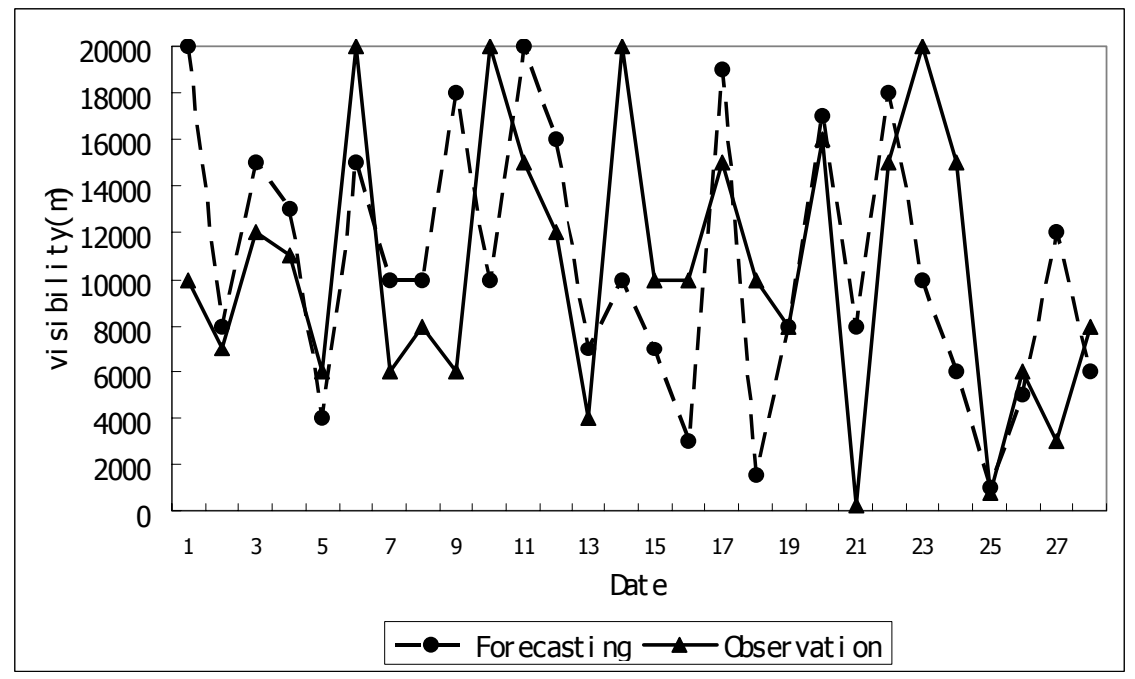

Figure 2: Comparison of visibility forecasting and observation in Feb.1-28, 2007 in Beijing.

The performance of the model and the observations in Feb. 2007 in Beijing are chosen as the samples of verification (Fig.2). According to the criterion of score in the meteorology department, there are three grades for scoring $(\mathrm{V}>5 \mathrm{~km}$, $1 \mathrm{~km}<\mathrm{V} \leq 5 \mathrm{~km}$ and $\mathrm{V} \leq 1 \mathrm{~km}$ ). The CSI (Critical Success Index) of Feb. 2007 is $89 \%$. In fact, there were two fog events occurring on 21 st and 25 th, one was a failure, and another was successful. Although the forecast of Beijing on 21st was 
a failure, the other places along the highway got a satisfactory forecast instead (the detailed description is shown in 4.1). The forecast and warning of two events were issued, therefore, the service obtained good effects.

According to the operational experiences, the successful proportion of forecasting for fog ending time is higher than the beginning time. This is because the NWP has better performance on the turning point of weather changes. Comparing with the fog forecast, the technology of forecasting no fog is relative simple, for example, it can tell from an increase of wind speed or a decrease of relative humidity.

\section{The forecasts of two heavy fog events}

\subsection{The forecast of regional dense fog}

On Feb. 21, 2007, during the Chinese traditional spring festival, a dense fog occurred in the Huabei Region area, at Beijing Capital Airport, the visibility suddenly decreased from $1500 \mathrm{~m}$ to $50 \mathrm{~m}$, and the low visibility lasted into the night, which caused hundreds of planes to cancel or delay. It brought seriously adverse impacts on economic benefits. Furthermore, the visibilities between Tianjin and Tanggu decreased from 200 meters to zero on some occasions.

The dense fog was forecasted by this fog model successfully. The outputs of forecast are showed in Tab.1.

Table 1: The outputs of visibility forecast for seven stations of the Jingjintang highway issued at 10:00 LST, on Feb.20, 2007 (Unit: meter).

\begin{tabular}{|l|c|c|c|c|c|c|c|}
\hline & Beijing & Langfang & Yangcun & Yixingfu & Dongli & Tianjin & Tanggu \\
\hline $14: 00,20^{\text {th }}$ & 10000 & 15000 & 12000 & 25000 & 10000 & 20000 & 8000 \\
\hline $20: 00$ & 10000 & 11000 & 10000 & 4000 & 2000 & 15000 & 7000 \\
\hline $02: 00,21^{\text {st }}$ & 7000 & 100 & 100 & 100 & 15000 & 100 & 18000 \\
\hline $08: 00$ & 8000 & 100 & 100 & 1500 & 699 & 1000 & 0 \\
\hline
\end{tabular}

From Table 1, it is shown that the forecast of visibility of Yixingfu and Dongli would decrease obviously at 20:00, and that of Langfang, Yangcun, Yixingfu and Tianjin would decrease to $100 \mathrm{~m}$ at 02:00 on the next day, namely there would be a low-visibility event occurring. Although the fog model showed the visibility of Beijing would not be as severe as other places, the visibilities of other stations would be in obviously decreasing trend and fall to terribly fuzzy. In operational experiences, if the visibilities of more than two stations decrease to below 1000 meters, there would be fog coming. Therefore, the heavy fog forecast and warning were issued. Since the highway was closed in time, there were no accidents on that day. 


\subsection{The forecast of local heavy fog}

Another example, on Feb. 25, 2007, the visibilities of Beijing Capital Airport and Beijing urban area were 2 to $3 \mathrm{~km}$ in the morning. And eastern and southern areas of Beijing were diffused with heavy fog, the visibilities varied from 800 meters to 100 meters. The fog gradually dispersed in the afternoon. The prediction was successful. The outputs of the fog model are showed in Tab. 2 .

Table 2: The outputs of visibility forecast along the Jing-jintang highway issued for seven stations at 20:00 LST, on Feb.24, 2007 (Unit: meter).

\begin{tabular}{|l|c|c|c|c|c|c|c|}
\hline & Beijing & Langfang & Yangcun & Yixingfu & Dongli & Tianjin & Tanggu \\
\hline $20: 00,24^{\text {th }}$ & 12000 & 10000 & 4000 & 20000 & 12000 & 15000 & 7000 \\
\hline $02: 00,25^{\text {th }}$ & 10000 & 10000 & 10000 & 10000 & 100 & 10000 & 1100 \\
\hline $08: 00$ & 10000 & 7000 & 2000 & 12000 & 100 & 800 & 0 \\
\hline $14: 00$ & 3000 & 1000 & 8000 & 15000 & 1100 & 10000 & 7000 \\
\hline
\end{tabular}

It was shown from Table 2, the visibility of Dongli would decrease obviously after midnight, then that of three stations would be lower in the next morning, the fog would disperse at 14:00. Therefore, the manager of the highway noticed that there would be heavy fog along the highway except for Beijing urban areas. In fact, the weather phenomenon coincided with the forecast.

\section{Tracking fog}

When the fog is occurring or is forecast to occur, managers of highway want to know the current fog report or very short-range forecast, such as fog extent, duration, intensity and position in time. But there are not enough AWS and human resources for supporting such an intensive fog observation. And the two forecasts cannot cover everywhere at anytime along the highway. It is hard to meet these needs.

Atmosphere monitoring means have made a great improvement in recent years. Satellites and their related processed products have been widely used in monitoring precipitation, tropical storms etc. in China. In this paper, a digital geostationary meteorological satellite MTSAT launched by Japan with $1 \mathrm{~km} \times 1.25 \mathrm{~km}$ resolutions is applied to detect fog. The fog could be discovered more clearly in (Fig. 3). The purpose is to make up the shortage of AWS over a broad area and to know the fog information in detail. The principle of data process is to distinguish the different characters in varying wavelengths. For instance, the fog has smooth edges in visible channel (0.5-1.1), similar temperature with ground in infrared channel (11), and specific reflectivity at higher heights (that can separate fog from cloud) in vapour channel (6.7). Fog can be discovered by combining the characters of multi-channels, surface observations and the elements of NWP at different heights. There are 48 satellite images that can be automatically obtained every day. The initialization and 
dissipation of fog could be identified by the satellite images (Fig.3). As well, the evolution of fog can be tracked by extrapolating or comparing images with each other. The accuracy of fog detection is about $80 \%$.

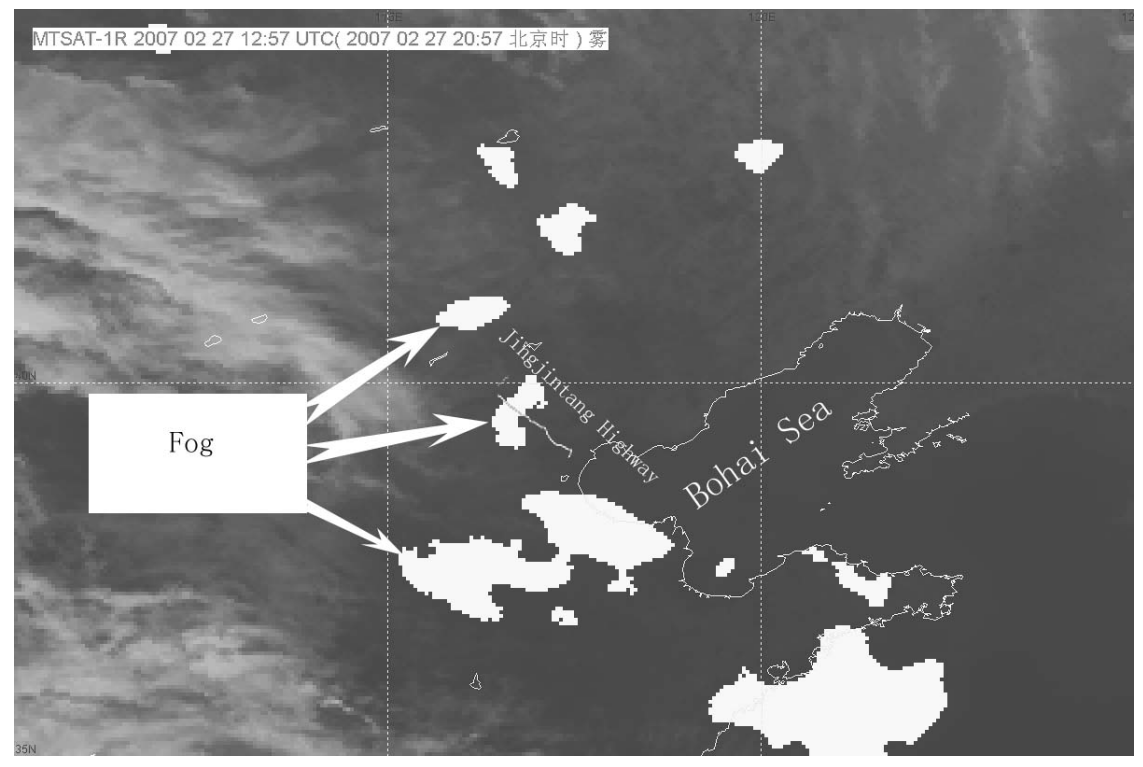

Figure 3: The processed satellite image of MTSAT by considering the characters of various channels at 20:57 LST on Feb. 27, 2007, Beijing.

\section{The service for the Jing-Jintang Highway}

Referring to the user's requirements, fog is the most significant weather which affects the transportation safety. This is because the whole highway lies on Huabei Plain neighboured to Bohai Sea with only a length of $230 \mathrm{Km}$. Therefore, most of time, the highway is influenced by the same weather. Besides, it is very hard to get frozen ice on road surfaces due to the drier continental climate in winter. Otherwise, there are no landslides while rainstorm occurs in summer. Therefore, the service focuses on whether it will have fog or not along the route.

BMB provides fog forecasts for the next 24 hours of seven places along the highway twice daily (in the morning and in the late afternoon). All the information is released through a specific internal website of users for the decision makers and their employees, and disseminated to the general public via various media.

Once there is unexpected occurrence of fog, the warning is issued by phone call and broadcast. In addition, some current reports of surface observation and monitoring images of geostationary satellite in Huabei Region are provided. 
The services achieve good effects and play an important role on ensuring the highway safety, the securities of people life and their properties.

\section{Conclusions}

1) The requirements of the weather service from the highway are highly associated with the economy. In addition, the government and general public have the same requirements.

2) Weather is the main influencing factor to transportation safety because of its high frequency and many types. Among the adverse weather, fog is the most severe weather causing casualties and serious losses along the Jing-Jintang highway.

3) To forecast whether there will be fog or not is a challenge for meteorologists. It can be solved by relying on combining with various tools rather than on single method. The new technologies such as wind profiler, radio metrics sounding and GPS vapour content should be put into strengthened use in the near future. Besides, the real time observations of road have essentially applicable values for service as well.

4) In this paper, the combination of conventional meteorological data, NWP and satellite is tentatively applied to forecast fog, what is of concern is that the methodology can be easily adopted by other places of China.

\section{References}

[1] M.T. Gu, Climate of North China Plain, Meteorological Press: Beijing, pp. 25-38, 1991.

[2] CROFT, P.J., MEDLIN, J.M. \& JOHNSON, G.A., Fog Forecasting for the Southern Region: A Conceptual Model Approach. American Meteorological Society: Weather and Forecast, Vol. (12), pp. 545-555, 1997.

[3] Ying. I. Tsai., Atmospheric visibility trend in an urban area in Taiwan 19612003. Atmospheric Environment, 39, pp. 5555-5567, 2005.

[4] X.F. Zhao, A Study on Regional Distribution of low Horizontal Visibility in Beijing Area. Meteorology Monthly, 28(11), pp. 55-58, 2002.

[5] Naegele, P.S., \& Sellers, W.D., A Study of visibility in Eighteen Cities in the Western and Southwestern United State. Monthly Weather Review, Vol. (109), pp. 2394-2399, 1982. 